\title{
Wittig-Type Olefination of Alcohols Promoted by Nickel Nanoparticles: Synthesis of Polymethoxylated and Polyhydroxylated Stilbenes
}

\author{
Francisco Alonso, ${ }^{*[a]}$ Paola Riente, ${ }^{[a]}$ and Miguel Yus*[a]
}

Keywords: Alcohols / Olefination / Nickel / Nanoparticles / Wittig reactions

Nickel nanoparticles were found to promote the Wittig-type olefination of primary alcohols with phosphorus ylides. The latter can be prepared from the corresponding phosphonium salts with $n \mathrm{BuLi}$ or in situ generated with lithium metal. The methodology is especially efficient for the synthesis of stilbenes and is applied in the absence of any additive as a hydrogen acceptor. A new approach to the synthesis of polymethoxylated and polyhydroxylated stilbenes, including resveratrol, DMU-212 and analogues, is presented.

(๔ Wiley-VCH Verlag GmbH \& Co. KGaA, 69451 Weinheim, Germany, 2009)

\section{Introduction}

The Wittig reaction ${ }^{[1]}$ was discovered in 1953 as a new and reliable method to form carbon-carbon double bonds. In a typical Wittig reaction, carbonyl compounds are treated with phosphorus ylides to give the corresponding alkenes and phosphane oxide. ${ }^{[2]}$ Sometimes, however, the carbonyl compound is not readily available and has to be prepared by oxidation of the precursor alcohol. In fact, the oxidation of primary alcohols to aldehydes and subsequent Wittig reaction is a common practice in organic synthesis. This strategy is advantageous, as it avoids the handling of aldehydes, especially when they are volatile, toxic or highly reactive. In addition, alcohols are, in general, cheaper, more commercially available, less toxic and more stable than the corresponding aldehydes. In this sense, a variety of oxidising systems have been implemented for the in situ oxidation-Wittig olefination of primary alcohols, namely, Swern, ${ }^{[3]} \mathrm{MnO}_{2},{ }^{[4]}$ Dess-Martin, ${ }^{[5]} \mathrm{BaMnO}_{4},{ }^{[6]} \mathrm{IBX},{ }^{[7]}$ TPAP, ${ }^{[8]} \mathrm{PCC},{ }^{[9]} \mathrm{SO}_{3} \cdot \mathrm{Py}^{[10]}$ and BAIB [bis(acetoxy)iodobenzene]-TEMPO. ${ }^{[11]}$ These procedures are primarily applied to stabilised ylides and, though in all cases the reactions are performed in one pot, some of them are sequential. Therefore, the course of the alcohol oxidation needs monitoring before the ylide addition. The activation of alcohols for the formation of carbon-carbon single bonds through an indirect Wittig olefination was pioneered by Williams et al. ${ }^{[12]}$ In this methodology, stabilised ylides and phosphonates were combined with benzyl alcohols in a domino Wittig-type olefination-transfer hydrogenation re-

[a] Departamento de Química Orgánica, Facultad de Ciencias, and Instituto de Síntesis Orgánica (ISO), Universidad de Alicante, Apdo. 99, 03080 Alicante, Spain Fax: +34-965903549

E-mail: falonso@ua.es, yus@ua.es

Supporting information for this article is available on the WWW under http://dx.doi.org/10.1002/ejoc.200900951. action, either under iridium or ruthenium homogeneous catalysis. As a result, products with a new carbon-carbon single bond, together with variable minor amounts of the corresponding aromatic aldehydes and alkenes, were obtained. Very recently, Park et al. reported the one-pot synthesis of $\alpha, \beta$-unsaturated esters from primary alcohols and stabilised Wittig reagents catalysed by $\mathrm{Ru} / \mathrm{AlO}(\mathrm{OH})$. The reaction proceeded in the presence of oxygen as the terminal oxidant and did not require any additive. ${ }^{[13]}$

In contrast, in recent years, both natural and synthetic polymethoxylated and polyhydroxylated stilbenes have attracted the attention of an important part of the scientific community as a result of their outstanding biological activity. ${ }^{[14]}$ Therefore, these molecules are considered as preferential targets from a synthetic point of view. ${ }^{[15]}$ Among them, resveratrol $\left[(E)-3,4^{\prime}, 5\right.$-trihydroxystilbene] is a naturally occurring phytoalexin present in vine bark, leaves and grapes, as well as in many other plants. ${ }^{[16]}$ A plethora of remarkable biological properties have been attributed to this special molecule, such as antioxidant, ${ }^{[16,17]}$ radioprotective, ${ }^{[16]}$ phytooestrogen, ${ }^{[16]}$ antibacterial ${ }^{[16]}$ and antifungal. ${ }^{[16]}$ Its therapeutic potential includes the chemoprevention of cancer, ${ }^{[16,18]}$ inflammation, ${ }^{[16]}$ aging, ${ }^{[16,19]}$ obesity $_{,}{ }^{16,20]}$ cardiovascular diseases ${ }^{[16]}$ and neurodegeneration. ${ }^{[16,21]}$ Interestingly, some methoxylated analogues of resveratrol exhibit a pharmacological profile comparable or even superior to that of resveratrol because of their higher lipophilicity. ${ }^{[22]}$ Such is the case of DMU-212 [(E)-3,4,4',5tetramethoxystilbene], which has recently disclosed a strong anticancer activity with higher chemoprotective activity than that of resveratrol. ${ }^{[23]}$

As part of our continuous interest in the preparation and application of active metals, ${ }^{[24]}$ we reported the fast synthesis of nickel(0) nanoparticles (NiNPs), from different nicke1(II) chloride-containing systems in THF, by using lithium powder and a catalytic amount of an arene, as reducing 


\section{Results and Discussion}

As in previous studies, the NiNPs were readily generated

agent, under mild conditions. ${ }^{[25]}$ These nanoparticles found application in different functional group transformations, ${ }^{[26]}$ as well as in the hydrogen transfer reduction of carbonyl compounds ${ }^{[27]}$ and reductive amination of aldehydes. ${ }^{[28]}$ We also discovered that nickel, in the form of nanoparticles, can activate alcohols for the $\alpha$-alkylation of ketones and indirect aza-Wittig reactions, with this being a potential alternative to noble-metal-based methodologies. ${ }^{[29]}$ These reactions involved hydrogen transfer from the alcohol to the intermediate $\alpha, \beta$-unsaturated ketone or imine, respectively. Moreover, in contrast with the use of noble-metal catalysts, the reactions proceeded in the absence of any added ligand, hydrogen acceptor or base, under mild conditions (Scheme 1).

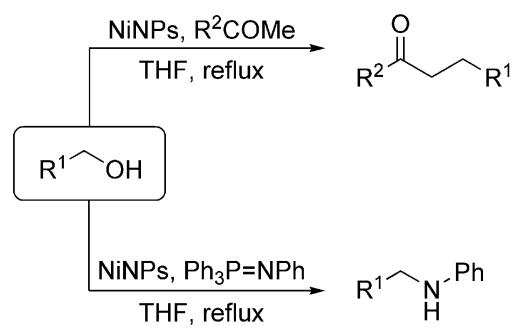

Scheme 1. $\alpha$-Alkylation of ketones and indirect aza-Wittig reaction with primary alcohols promoted by nickel nanoparticles.

In relation with the aforementioned antecedents, we recently studied the behaviour of the nickel nanoparticles in Wittig-type reactions by using alcohols as phosphorus ylide partners. ${ }^{[30]}$ In particular, we discovered that NiNPs, readily prepared from $\mathrm{NiCl}_{2}$, lithium metal and a catalytic amount of DTBB (4,4'-di-tert-butylbiphenyl) in THF, can promote the one-pot Wittig-type olefination of benzylidenetriphenylphosphorane with different benzyl alcohols. ${ }^{[30 a]}$ Furthermore, this reaction was used as the key step in a novel synthesis of resveratrol, DMU-212 and analogues. ${ }^{[30 \mathrm{~b}]}$ To the best of our knowledge, this is the first metal-promoted selective Wittig olefination reaction with alcohols (instead of aldehydes) in which there is no standard redox step. ${ }^{[31]}$ We wish to report herein a more detailed and complete study on this reaction, additionally including: (a) the alternative in situ generation of the phosphorus ylides, (b) the substrate scope, which is extended to non-benzylic substrates and (c) the synthesis of a wide range of polymethoxylated stilbenes.

from anhydrous nickel(II) chloride, lithium powder and a catalytic amount of DTBB ( $5 \mathrm{~mol}-\%)$ in THF at room temperature. ${ }^{[25]}$ First, we optimised the amount of catalyst by treating benzyl alcohol and benzylidenetriphenylphosphorane (previously generated from commercially available benzyltriphenylphosphonium chloride and $n \mathrm{BuLi}$ ) in THF at reflux (Table 1). The reaction did not occur in the ab- sence of any nickel catalyst, leading to the unmodified starting materials (Table 1, Entry 1). A 1:1 NiNPs/substrate ratio, however, afforded stilbene in $77 \%$ isolated yield as a ca. 1:1 cis/trans mixture in $6 \mathrm{~h}$ (Table 1, Entry 2). Unfortunately, no reaction was observed for a lower NiNPs/substrate ratio (Table 1, Entry 3 ). The reactivity of the NiNPs in the model reaction was compared with that of commercially available nickel catalysts. To our delight, Raney nickel (Table 1, Entry 4), Ni-Al alloy (Table 1, Entry 5) and Ni/ $\mathrm{SiO}_{2}-\mathrm{Al}_{2} \mathrm{O}_{3}$ (Table 1, Entry 6) were shown to be inactive under the same conditions as those in Entry 2 (Table 1). Interestingly, we found that the phosphorus ylide could be alternatively obtained in situ from the corresponding phosphonium salt and an excess amount ( 2 equiv.) of the lithium metal used for the generation of the NiNPs. This method simplifies the experimental procedure, although stilbene was obtained in a lower yield (Table 1, Entry 7).

Table 1. Wittig-type olefination of benzyl alcohol and benzylidenetriphenylphosphorane in the presence of different nickel catalysts. [1 $((<=$ Author: change to table ok? $))$

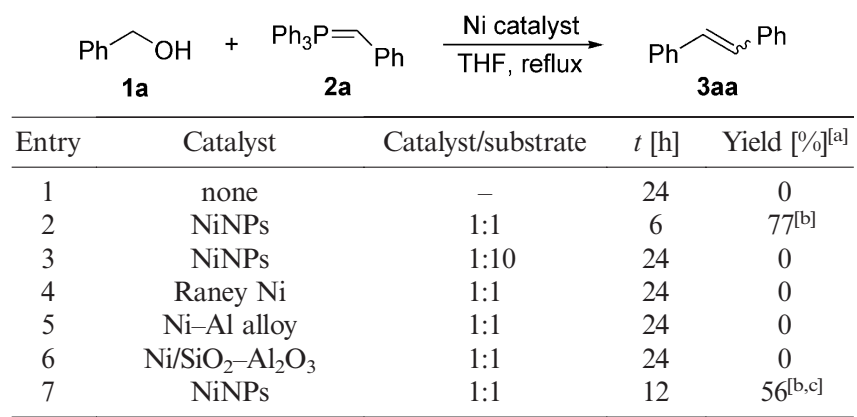

[a] GLC yield, unless otherwise stated. [b] Isolated yield after column chromatography as a ca. 1:1 cis/trans mixture. [c] Compound 2a was generated in situ from benzyltriphenylphosphonium chloride and lithium metal.

The optimised reaction conditions (Scheme 2), with both the phosphorus ylide previously generated with $n \mathrm{BuLi}$ $(\operatorname{method} A)$ or in situ generated with lithium (method B), were extended to a variety of benzyl alcohols (Table 2). The reaction time, yield and diastereoselectivity were shown to be dependent on the electronic character and position of the substituents, as well as on the preparation method of the ylide. For instance, 4-methylbenzyl alcohol (1b) and 3methylbenzyl alcohol (1c) provided the corresponding stilbenes $\mathbf{3 b a}$ and $\mathbf{3} \mathbf{c a}$ in high yields after $8 \mathrm{~h}$ with method $\mathrm{A}$ (Table 2, Entries 2 and 3). In these cases, however, the yields were rather low with method B. Surprisingly, 2-methylbenzyl alcohol (1d) did not react under the conditions of method A but the expected stilbene could be obtained in modest yield by method B (Table 2, Entry 4). Lower reactivity was displayed by the electron-deficient trifluoromethyl-substituted benzyl alcohols 1e and 1f (Table 2, Entries 5 and 6). The corresponding olefins were obtained in moderate yields after longer heating, independently of the method used. In contrast, moderate-to-good yields of stilbenes were achieved for methoxy-substituted benzyl 
161 alcohols (Table 2, Entries 7-9). The reaction was faster when the methoxy group was located at the para and meta positions, albeit the highest yield was reached for 2-methoxybenzyl alcohol (1i) by method A (Table 2, Entry 9). It is

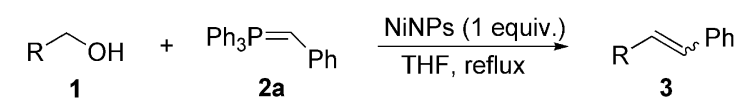

Scheme 2. Alcohol (1 mmol), phosphorus ylide (1 mmol), NiNPs (1 mmol), THF (4 mL). noteworthy that method B improved the yield of stilbene 3ga (Table 2, Entry 7) but lowered that of 3ia (Table 2, Entry 9). Method A was the method of choice for the olefination of furan-2-ylmethanol (1j) and piperonyl alcohol $(\mathbf{1 m})$, whereas polymethoxylated benzyl alcohols $1 \mathbf{k}$ and $\mathbf{1 l}$ furnished the expected alkenes in good isolated yields, irrespective of the method used (Table 2, Entries 10-12). The substrate scope seemed to be more limited in the case of alkyl alcohols. Nonetheless, $n$-hexanol (1n) and cyclopentylmethanol (10) gave the corresponding alkenes 3na and

Table 2. Wittig-type olefination of primary alcohols with benzylidenetriphenylphosphorane promoted by nickel nanoparticles.

\begin{tabular}{|c|c|c|c|c|c|c|c|}
\hline Entry & Alcohol & & $t[\mathrm{~h}]^{[\mathrm{a}]}$ & Product & & $Z / E^{[a, b]}$ & Yield $[\%]^{[a, c}$ \\
\hline 1 & & $1 a$ & $6\{12\}$ & & 3aa & $\begin{array}{c}51: 49 \\
\{54: 46\}\end{array}$ & $\begin{array}{c}77 \\
(Z 36, E 41) \\
\{56\}\end{array}$ \\
\hline 2 & & $1 \mathrm{~b}$ & $8\{6\}$ & & $3 \mathrm{ba}$ & $\begin{array}{c}36: 64 \\
\{46: 54\}\end{array}$ & $\begin{array}{c}81 \\
(Z 31, E 50) \\
\{52\}\end{array}$ \\
\hline 3 & & $1 c$ & $8\{4\}$ & & $3 \mathrm{ca}$ & $\begin{array}{c}42: 58 \\
\{53: 47\}\end{array}$ & $\begin{array}{c}86 \\
(Z 41, E 45) \\
\{47\}\end{array}$ \\
\hline 4 & & 1d & $\{4\}$ & & 3da & $\{44: 56\}$ & $\begin{array}{c}\{28\} \\
(Z 18, E 10)\end{array}$ \\
\hline 5 & & $1 e$ & $30\{12\}$ & & 3ea & $\begin{array}{c}21: 79 \\
\{32: 68\}\end{array}$ & $41\{54\}$ \\
\hline 6 & & $1 \mathrm{f}$ & 24 & & $3 f a$ & $25: 75$ & $\begin{array}{c}51 \\
(Z 13, E 38)\end{array}$ \\
\hline 7 & & $1 \mathrm{~g}$ & $4\{4\}$ & & 3ga & $\begin{array}{l}57: 43 \\
\{54: 46\}\end{array}$ & $67\{76\}$ \\
\hline 8 & & $1 \mathrm{~h}$ & $4\{12\}$ & & 3ha & $\begin{array}{c}53: 47 \\
\{52: 48\}\end{array}$ & $62\{59\}$ \\
\hline 9 & & $1 \mathrm{i}$ & $20\{24\}$ & & $3 \mathbf{i a}$ & $\begin{array}{c}36: 64 \\
\{37: 63\}\end{array}$ & $83\{43\}$ \\
\hline 10 & & $1 \mathrm{j}$ & $6\{12\}$ & & 3ja & $\begin{array}{c}51: 49 \\
\{35: 65\}\end{array}$ & $70\{31\}$ \\
\hline 11 & & $1 \mathrm{k}$ & $15\{10\}$ & & 3ka & $\begin{array}{c}24: 76 \\
\{47: 53\}\end{array}$ & $67\{65\}$ \\
\hline 12 & & 11 & $24\{48\}$ & & 3la & $\begin{array}{c}47: 53 \\
\{44: 56\}\end{array}$ & $\begin{array}{c}70 \\
(Z 30, E 40) \\
\{64\}\end{array}$ \\
\hline 13 & & $1 \mathrm{~m}$ & 10 & & $3 m a$ & 50:50 & 74 \\
\hline 14 & & $1 \mathrm{n}$ & $24\{5\}$ & & 3 na & $\begin{array}{c}65: 35 \\
\{32: 68\}\end{array}$ & $40\{58\}$ \\
\hline 15 & & 10 & $8\{12\}$ & & 3oa & $\begin{array}{c}26: 74 \\
\{32: 68\}\end{array}$ & $70\{48\}$ \\
\hline
\end{tabular}

[a] Values in curly brackets obtained by in situ generation of the phosphorus ylide with lithium metal (method B). [b] $Z / E$ ratio determined from the crude product by GLC and/or ${ }^{1} \mathrm{H}$ NMR spectroscopy. [c] Isolated yield after column chromatography; the isolated yield for each stereoisomer is given in parentheses. 
3oa in moderate-to-good yields (Table 2, Entries 14 and 15, respectively). Curiously, method $\mathrm{B}$ was proven to be faster and higher yielding for 3na, whereas method A was more effective for $\mathbf{3 0 a}$.

In general, the process displayed low diastereoselectivity, mainly in favour of the $E$ diastereoisomer. It is well known

181 that benzyl ylides are semistabilised ylides leading to $Z / E$ mixtures. ${ }^{[32]}$ In particular, the reactions with benzylidenetriphenylphosphorane and aromatic aldehydes are practically nonselective. It was reported that the presence of a lithium salt slightly increased the diastereoselectivity in favour of

186 the $Z$ stereoisomer (ca. 60:40), ${ }^{[32]}$ whereas a catalytic amount of 18 -crown- 6 notably improved the $Z$ stereoselectivity. ${ }^{[33]}$ In our study, a maximum ca. 1:4 Z/E ratio of diastereomeric stilbenes was obtained for alcohol 1e (Table 2, Entry 5). The lithium chloride present in the reaction me-

191 dium (from the reduction of $\mathrm{NiCl}_{2}$ with $\mathrm{Li}$ ) seems not to exert any positive effect concerning the stereoselectivity. Nevertheless, the purification step by column chromatography allowed the separation of both stereoisomers for some stilbenes (Table 2, Entries 1-4, 6 and 12). Fortunately, $Z$ to $E$ isomerisation was easily accomplished under iodine catalysis. ${ }^{[2 \mathrm{~b}]}$ For instance, a 57:43 Z/E mixture of 1-(4methoxyphenyl)-2-phenylethene (3ga) was quantitatively converted into the corresponding $E$ stereoisomer by treatment with a catalytic amount of iodine in hexane at reflux (Scheme 3).
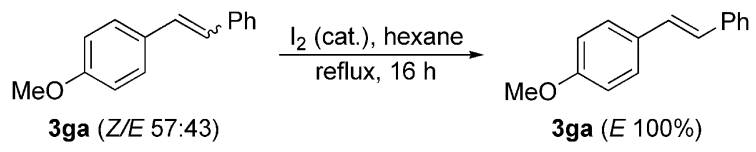

Scheme 3. Iodine-catalysed $Z / E$ isomerisation of 1-(4-methoxyphenyl)-2-phenylethene.
The Wittig-type olefination reaction was extended to the reaction of various benzyl alcohols with nonstabilised ylides $\mathbf{2 b}$ and $\mathbf{2 c}$, derived from commercially available ( $n$-pentyl)triphenylphosphonium and methyltriphenylphosphonium bromides, respectively (Table 3 ). The NiNPs exhibited a lower activity in promoting these reactions, with the corresponding alkenes being obtained in modest-to-moderate isolated yields, independently on the method of synthesis of the ylide.

As a result of the abundance of polymethoxylated stilbenes in nature, ${ }^{[14]}$ we decided to synthesise a variety of this type of compounds by applying the above-mentioned methodology (Table 4). In all cases, the phosphorus ylide was previously prepared with $n \mathrm{BuLi}(\operatorname{method} \mathrm{A})$. Monomethoxylated ylide 2d was coupled with the three regioisomeric methoxybenzyl alcohols $\mathbf{1 g}-\mathbf{i}$, with the corresponding dimethoxylated stilbenes being obtained in moderate-to-good yields (Table 4, Entries 1-3). The highest yield was achieved for the olefination reaction of piperonyl alcohol (1m) and ylide 2d (Table 4, Entry 4). Other polymethoxylated stilbenes were also prepared in good-to-high yields from the corresponding polymethoxylated benzyl alcohols and ylide partners (Table 4, Entries 5-7). The reaction of meta-substituted monomethoxy- and dimethoxybenzyl alcohols $\mathbf{1 h}$ and $\mathbf{1 k}$ with $\mathbf{2 d}$ and $\mathbf{2 e}$ led to $\mathbf{3 h d}$ and the symmetrically substituted polymethoxylated stilbene 3ke with highest diastereoselectivities (Z/E ca. 1:7; Table 4, Entries 2 and 6, respectively). Chromatographic separation of the $Z$ and $E$ isomers was possible in most cases (Table 4, Entries 1, 2 and 4-6).

It is worthwhile mentioning that the success of this olefination methodology resides in the fact that, in contrast with the work of Williams, ${ }^{[12]}$ hydrogen transfer from the alcohol to the corresponding stilbene is not effective. In

Table 3. Wittig-type olefination of benzyl alcohols with nonstabilised phosphorus ylides promoted by nickel nanoparticles.

Entry

[a] Values in curly brackets obtained by in situ generation of the phosphorus ylide with lithium metal (method B). [b] Z/E ratio determined from the crude product by GLC and/or ${ }^{1} \mathrm{H}$ NMR spectroscopy. [c] Isolated yield after column chromatography. 
Table 4. Synthesis of polymethoxylated stilbenes by Wittig-type olefination of benzyl alcohols and phosphorus ylides promoted by nickel nanoparticles. ${ }^{[a]}$

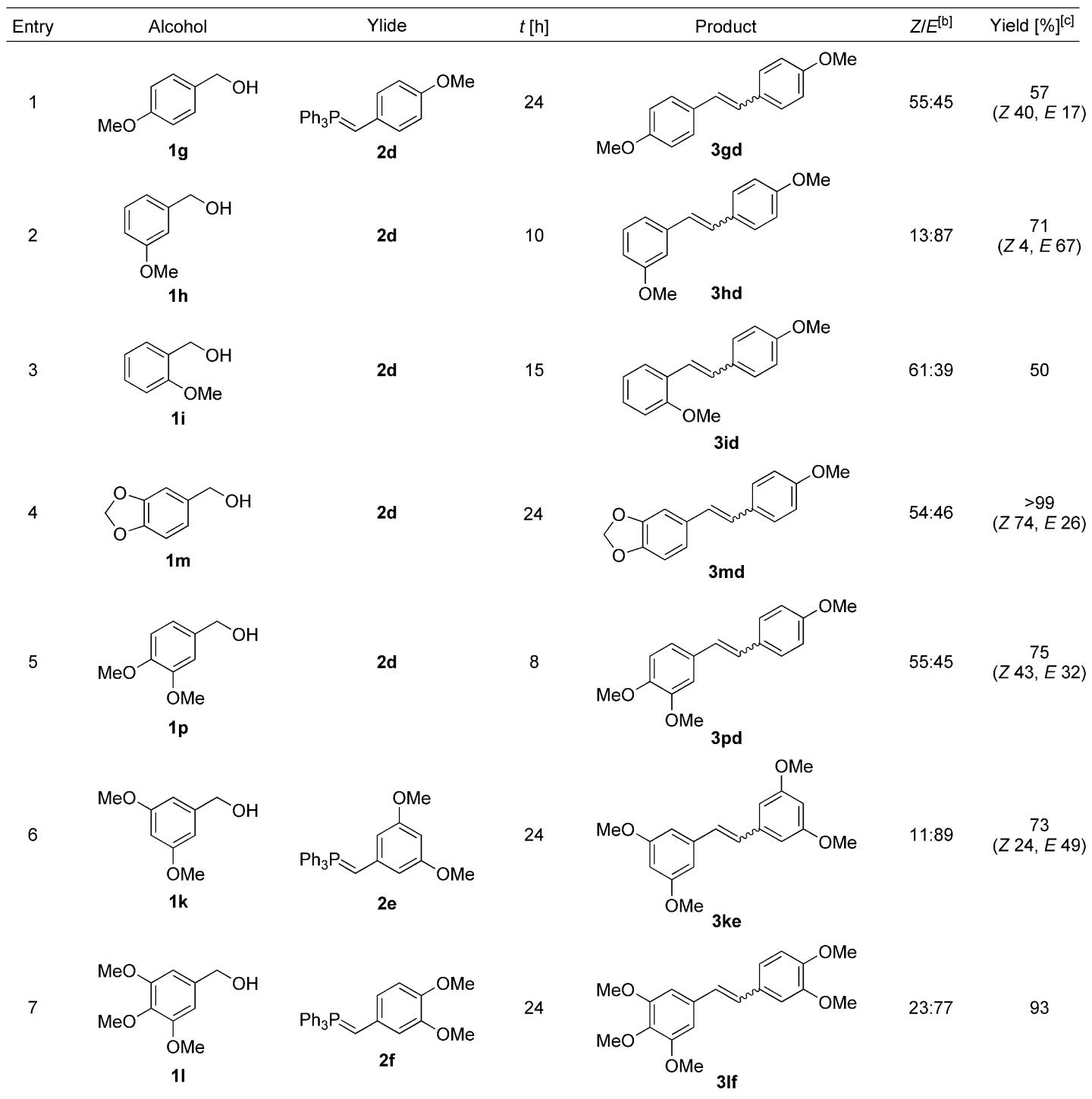

[a] Alcohol (1 mmol), $\mathrm{Ph}_{3} \mathrm{P}=\mathrm{CHAr}(1 \mathrm{mmol}), \mathrm{NPsNi}(1 \mathrm{mmol}), \mathrm{THF}(4 \mathrm{~mL}), 76^{\circ} \mathrm{C}$. [b] $\mathrm{Z} / E$ ratio determined from the crude product by GLC and/or ${ }^{1} \mathrm{H}$ NMR spectroscopy. [c] Isolated yield after column chromatography; the isolated yield for each stereoisomer is given in parentheses.

fact, we never detected the corresponding dihydrostilbenes. In principle, this behaviour was unexpected and might be attributed either to preferential hydrogen transfer to some other species present in the reaction medium or to a loss of the catalyst activity during the reaction. The first argument was ruled out, as different experiments to test the possible hydrogen transfer from benzyl alcohol to either the phosphorus ylide or triphenylphosphane oxide failed. We found, however, that the hydrogen transfer reduction of stilbene with benzyl alcohol was substantially depleted in the presence of the phosphorus ylide, triphenylphosphane oxide or triphenylphosphane. It is well known that phosphorus compounds can bind strongly to metal centres, therefore blocking access of the substrate to the active site. ${ }^{[34]}$ Transmission electron microscopy images, obtained before and after a standard olefination reaction, revealed an increase in the size of the NiNPs from $2.5 \pm 1.5 \mathrm{~nm}$ to $8-20 \mathrm{~nm}$ (Figure 1). From these results, it can be inferred that catalyst deactiva-
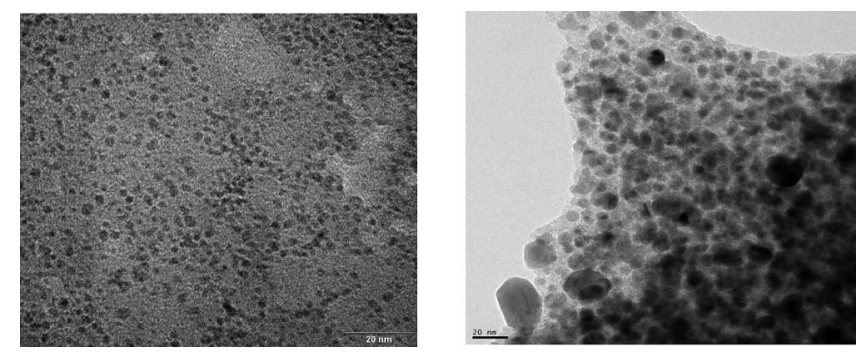

Figure 1. TEM micrograph of the NiNPs before (left) and after (right) a Wittig-type olefination. 


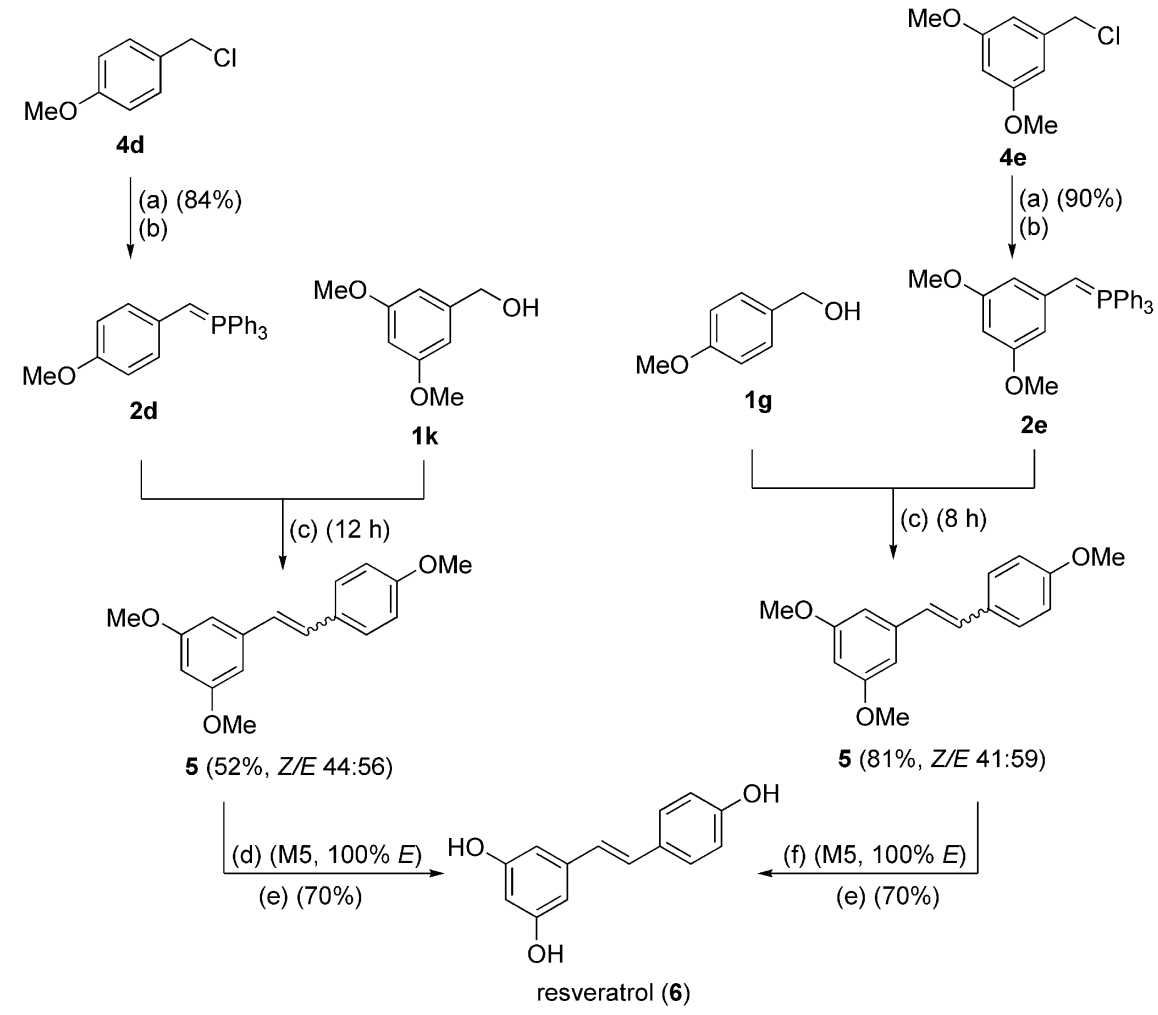

Scheme 4. (a) $\mathrm{PPh}_{3}, \mathrm{PhMe}$, reflux, 6 h; (b) $n \mathrm{BuLi}$, THF, $0{ }^{\circ} \mathrm{C}, 20$ min; (c) NiNPs, THF, reflux; (d) cat. $\mathrm{I}_{2}$, hexane, reflux, 48 h; (e) $\mathrm{BBr}{ }_{3}$, $\mathrm{CH}_{2} \mathrm{Cl}_{2}, 0^{\circ} \mathrm{C}$ to r.t., $5 \mathrm{~h}$; (f) $(\mathrm{PhS})_{2}$, AIBN, THF, reflux, $8 \mathrm{~h}$.

tion by poisoning with phosphorus compounds, together with some nanoparticle agglomeration, are very likely the main reasons that account for this particular performance.

As a result of the successful synthesis of polymethoxylated stilbenes by the NiNPs-promoted Wittig-type olefination of alcohols, we turned our attention to the synthesis of some stilbenes of prominent biological activity, such 261 as resveratrol, DMU-212 and analogues. With regard to the synthesis of resveratrol, we attempted two different approaches starting from commercially available benzyl halides $\mathbf{4 d}$ and $\mathbf{4 e}$ (Scheme 4). In the first approach, 4d was transformed into the corresponding phosphonium salt in good yield, followed by deprotonation with $n$ BuLi. Wittigtype olefination of the resulting benzyl phosphorus ylide $\mathbf{2 d}$ with 3,5-dimethoxybenzyl alcohol (1k) furnished methylated resveratrol (5) in moderate yield as a 44:56 Z/E mixture of diastereoisomers. Iodine-catalysed isomerisation of $(Z)$ 5 into (E)-5 (M5) and subsequent demethylation with $\mathrm{BBr}_{3}$ afforded resveratrol (6) in $31 \%$ overall yield.

In a second approach, Wittig partners $\mathbf{1 k}$ and $\mathbf{2 d}$ were changed into $\mathbf{1 g}$ and $\mathbf{2 e}$, respectively (Scheme 4). Following the above-described steps, a higher yield was obtained for the phosphonium salt derived from $4 \mathbf{e}$ in comparison with that of $4 \mathbf{d}$. The Wittig-type olefination of ylide $2 \mathbf{e}$ and benzyl alcohol $1 \mathrm{~g}$ was shown to be faster and higher yielding than that in the first approach. The $Z$ to $E$ isomerisation of 5 was catalysed in this case by diphenyl disulfide in the presence of $\mathrm{AIBN},{ }^{[35]}$ with a notable reduction in the reac- tion time (48 vs. $8 \mathrm{~h}$ ). Final treatment with $\mathrm{BBr}_{3}$ led to resveratrol in $51 \%$ overall yield. This yield is comparable to that obtained with the decarbonylative Heck reaction from resorcylic acid, which, to the best of our knowledge, is the most effective synthesis reported so far. ${ }^{[36]}$

On the basis of a similar strategy, we undertook the synthesis of DMU-212 [E-(7)] (Scheme 5). In the first synthetic variant, phosphorus ylide $\mathbf{2 l}$ was prepared in high yield by bromination of benzyl alcohol 11, followed by phosphonium salt formation and deprotonation. The olefination of $\mathbf{2 l}$ with benzyl alcohol $1 \mathrm{~g}$ led to 7 in $64 \%$ yield as a $46: 54 \mathrm{Zl}$ $E$ diastereomeric mixture. A $50 \%$ overall yield of $(Z / E)-7$ was achieved after three synthetic steps prior to isomerisation. In the search for a more effective variant, we discovered that the Wittig-type olefination reaction proceeded quantitatively by changing $\mathbf{2}$ and $\mathbf{1 g}$ into $\mathbf{2 d}$ and $\mathbf{1 1}$, respectively. To our delight, in this case DMU-212 (7) was obtained as a single diastereoisomer in $84 \%$ overall yield after two synthetic steps from commercially available $\mathbf{4 d}$. In principle, the high diastereoselectivity obtained in the synthesis of 7 was unexpected. We observed, however, that these types of compounds can undergo partial isomerisation during their handling (e.g., in $\mathrm{CDCl}_{3}$ ). In addition, resveratrol and methoxylated analogues have been reported to be photosensitive. ${ }^{[37]}$ Therefore, there may be some parameters that are difficult to control or that go unnoticed that could condition the final diastereoselectivity of the reaction. $((<=$ Author: change ok?)) 
<smiles>COc1cc(CO)cc(OC)c1OC</smiles><smiles>COc1ccc(CO)cc1</smiles>

$1 \mathrm{~g}$
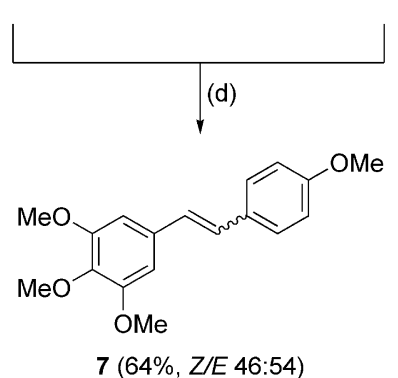

(b) $(90 \%)$ (c)<smiles>COc1cc(/C=[P+]\c2ccccc2)cc(OC)c1OC</smiles><smiles>COc1cc(CO)cc(OC)c1OC</smiles>

11<smiles>COc1ccc(CCl)cc1</smiles>

4d

(b) $(84 \%)$
(c)<smiles>COc1ccc(/C=[P+]\c2ccccc2)cc1</smiles>
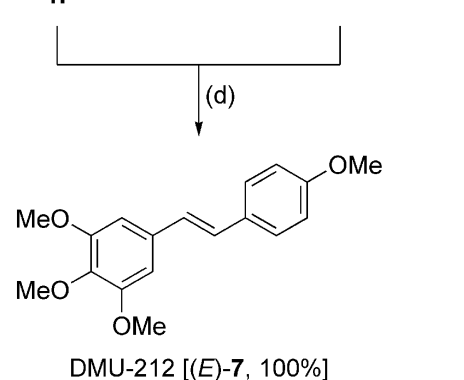

Scheme 5. (a) $\mathrm{PBr}_{3}, \mathrm{CH}_{2} \mathrm{Cl}_{2}, 0{ }^{\circ} \mathrm{C}$ to r.t., overnight; (b) $\mathrm{PPh}_{3}$, PhMe, reflux, 6 h; (c) $n \mathrm{BuLi}, \mathrm{THF}, 0{ }^{\circ} \mathrm{C}, 20$ min; (d) NiNPs, THF, reflux, $12 \mathrm{~h}$.

Finally, we dealt with the synthesis of the highly polymethoxylated and polyhydroxylated stilbenoids dehydrobrittonin A (8) ${ }^{[38]}$ and M8 (9). In particular, M8 (9) was recently found to exhibit many remarkable biological effects,

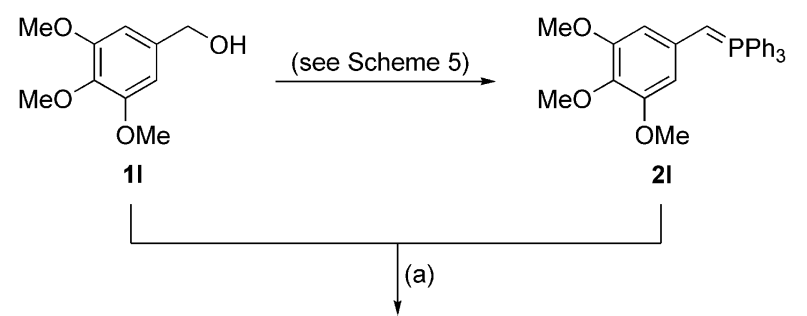<smiles>COc1cc(C=Cc2cc(OC)c(OC)c(OC)c2)cc(OC)c1OC</smiles>

dehydrobrittonin $\mathrm{A}(\mathbf{8}, 61 \%$, Z/E 46:54)

(b) $(8,100 \% E)$ (c) $(45 \%)$<smiles>C[As](C)(=O)(O)c1cc(/C=C/c2cc(O)c(O)c(O)c2)cc(O)c1O</smiles>

Scheme 6. (a) NiNPs, THF, reflux, $24 \mathrm{~h}$; (b) $(\mathrm{PhS})_{2}, \mathrm{AIBN}, \mathrm{THF}$, reflux, $8 \mathrm{~h}$; (c) $\mathrm{BBr}_{3}, \mathrm{CH}_{2} \mathrm{Cl}_{2},-30{ }^{\circ} \mathrm{C}$ to r.t., $5 \mathrm{~h}$. including, highly selective cyclooxygenase-2 inhibition, ${ }^{[39]}$ much higher antioxidant activity than resveratrol in different leukemic cell lines, ${ }^{[40]}$ apoptosis induction at concentrations significantly lower than resveratrol in HL-60 human promyelocytic leukemia cells ${ }^{[41]}$ and apoptosis induction and cell cycle arrest in prostate cancer [also observed for DMU-212 (7) $]^{[42]}$ and HT29 human colon cancer cells [also observed for M5, $(E)-5] .^{[43]}$

Dehydrobrittonin A $\left(\mathbf{8}, 3,3^{\prime}, 4,4^{\prime}, 5,5^{\prime}\right.$-hexamethoxystilbene) is a symmetrically substituted stilbene, the synthesis of which was accomplished from 3,4,5-trimethoxybenzyl alcohol (11) as the only starting material (Scheme 6). This alcohol had a double role, acting as both the precursor of ylide $\mathbf{2 l}$ and its partner in the NiNPs-promoted Wittig-type olefination. The latter reaction was slower in comparison with those involving homologue substrates with a lower number of methoxy groups. Notwithstanding, expected stilbene 8 was obtained in moderate yield as a mixture of diastereoisomers. Quantitative radical isomerisation of $(Z)-\mathbf{8}$ into $(E)-\mathbf{8}$ followed by demethylation ${ }^{[39]}$ afforded the resveratrol analogue M8 [9, (E)-3,3',4,4',5,5'-hexahydroxystilbene].

\section{Conclusions}

We have demonstrated for the first time that nickel, in the form of nanoparticles, can promote the Wittig-type reaction of primary alcohols and phosphorus ylides. The latter could be previously prepared from the corresponding phosphonium salts by deprotonation with $n \mathrm{BuLi}$ or generated in situ with lithium metal. The NiNPs were shown to be catalytically superior to other forms of nickel in this re- 
action. The reaction works especially well for benzyl alcohols and semistabilised benzyl ylides, whereas the sub-

346 strate scope is more limited in the case of alkyl alcohols or nonstabilised ylides. In the former case, a wide range of stilbenes were obtained in modest-to-high isolated yields, depending on the electronic character of the substituent and position in the aromatic ring. In general, the process exhib-

351 its low diastereoselectivity, though the $Z / E$ mixtures could be separated, in some cases, by column chromatography or quantitatively transformed into the $E$ stereoisomers by iodine-catalysed or radical isomerisation. To the best of our knowledge, this is the first metal-mediated chemoselective Wittig-type olefination reaction with alcohols, in which there is no standard redox step. Moreover, the reaction proceeds in the absence of any additive as a hydrogen acceptor. A series of polymethoxylated stilbenes as well as resveratrol, DMU-212 and analogues, such as M5, dehydrobrittonin A 361 or M8, were synthesised by using this novel Wittig-type olefination as the key step.

\section{Experimental Section}

General Procedure for the NiNPs-Promoted Wittig-Type Olefination of Primary Alcohols and Phosphorus Ylides

Method A: $n \mathrm{BuLi}(1.6 \mathrm{M}$ in $\mathrm{xxx}$, ((<=Author: solvent?)) $625 \mu \mathrm{L}, 1.0 \mathrm{mmol})$ was added dropwise to a suspension of the corresponding phosphonium halide $(1.5 \mathrm{mmol})$ in THF $(2 \mathrm{~mL})$ at $0{ }^{\circ} \mathrm{C}$. While the corresponding ylide was being formed (ca. $20 \mathrm{~min}$ ), nickel(II) chloride (130 mg, $1 \mathrm{mmol}$ ) was added over a suspension 371 of lithium (14 mg, $2 \mathrm{mmol}$ ) and DTBB (13 mg, $0.05 \mathrm{mmol})$ in THF $(2 \mathrm{~mL})$ at room temperature under an atmosphere of argon. The reaction mixture, which was initially dark blue, changed to black, indicating that nickel( $(0)$ was formed. After $10 \mathrm{~min}$, the corresponding benzyl alcohol $(1 \mathrm{mmol})$ and the initially prepared ylide suspension were added to the NiNPs suspension. The reaction mixture was warmed to reflux and monitored by GLC-MS. The resulting mixture was diluted with EtOAc $(10 \mathrm{~mL})$, filtered through a pad of Celite and the filtrate was dried with anhydrous $\mathrm{MgSO}_{4}$. The residue obtained after removal of the solvent (15 Torr) was purified by

381 column chromatography (silica gel, hexane or hexane/EtOAc) to give the pure product.

Method B: Following method A but the phosphorus ylide was generated in situ (ca. $20 \mathrm{~min}$ ) by addition of the phosphonium halide to a NiNPs suspension, prepared as aforementioned by using an 386 excess amount of lithium powder $(28 \mathrm{mg}, 4 \mathrm{mmol})$. Then, the corresponding alcohol was added to the resulting mixture. The diastereomeric ratio was determined on the basis of the GC and ${ }^{1} \mathrm{H}$ NMR spectroscopic analyses.

Supporting Information (see also the footnote on the first page of 391 this article): General experimental details, methods and compound characterisation data.

\section{Acknowledgments}

This work was generously supported by the Spanish Ministerio de Educación y Ciencia (MEC) (grant no. CTQ2007-65218 and Con396 solider Ingenio 2010-CSD2007-00006). P. R. thanks the MEC for a predoctoral grant.
[1] G. Wittig, G. Geissler, Justus Liebigs Ann. Chem. 1953, 580, 44-57.

[2] For reviews, see: a) B. E. Maryanoff, A. B. Reitz, Chem. Rev. 1989, 89, 863-927; b) M. Edmonds, A. Abell in Modern Carbonyl Olefination (Ed.: T. Takeda), Wiley-VCH, Weinheim, 2009, pp. 1-17.

[3] R. E. Ireland, D. W. Norbeck, J. Org. Chem. 1985, 50, 2198 2200.

[4] a) For a review, see: R. J. K. Taylor, M. Reid, J. Foot, S. A. Raw, Acc. Chem. Res. 2005, 38, 851-869; b) For a recent application, see: D. J. Phillips, A. E. Graham, Synlett 2008, 649-652.

[5] A. G. M. Barrett, D. Hamprecht, M. Ohkubo, J. Org. Chem. 1997, 62, 9376-9378.

[6] S. Shuto, S. Niizuma, A. Matsuda, J. Org. Chem. 1998, 63, 4489-4493.

[7] A. Maiti, J. S. Yadav, Synth. Commun. 2001, 31, 1499-1506.

[8] R. N. MacCoss, E. P. Balskus, S. V. Ley, Tetrahedron Lett. 2003, 44, 7779-7781.

[9] a) A. R. Bressette, L. C. Glover IV, Synlett 2004, 738-740; b) J. Shet, V. Desai, S. Tilve, Synthesis 2004, 1859-1863.

[10] F. R. Pinacho Crisostomo, R. Carrillo, T. Martin, F. GarciaTellado, V. S. Martin, J. Org. Chem. 2005, 70, 10099-10101.

[11] J. M. Vatèle, Tetrahedron Lett. 2006, 47, 715-718.

[12] For reviews, see: a) M. H. S. Hamid, P. A. Slatford, J. M. J. Williams, Adv. Synth. Catal. 2007, 349, 1555-1575; b) T. D. Nixon, M. K. Whittlesey, J. M. J. Williams, Dalton Trans. 2009, 753762.

[13] E. Y. Lee, Y. Kim, J. S. Lee, J. Park, Eur. J. Org. Chem. 2009, 2943-2946.

[14] a) J. Gorham, The Chemistry of the Stilbenoids, Chapman \& Hall, London, 1995. See, for instance: b) E. Garo, J.-F. Hu, M. Goering, G. Hough, M. O'Neil-Johnson, G. Eldridge, J. Nat. Prod. 2007, 70, 968-973; c) R. Siles, J. F. Ackley, M. B. Hadimani, J. J. Hall, B. E. Mugabe, R. Guddneppanavar, K. A. Monk, J.-C. Chapuis, G. R. Petit, D. J. Chaplin, K. Edvardsen, M. L. Trawick, C. M. Garner, K. G. Pinney, J. Nat. Prod. 2008, 71, 313-320; d) A. Gosslau, S. Pabbaraja, S. Knapp, K. Y. Chen, Eur. J. Pharmacol. 2008, 587, 25-34.

[15] For a review, see: K. Ferré-Filmon, L. Delaude, A. Demonceau, A. F. Noels, Coord. Chem. Rev. 2004, 248, $2323-$ 2336.

[16] For a monograph, see: B. B. Aggarwall, S. Shishodia (Eds.), Resveratrol in Health and Disease, Taylor \& Francis, Boca Raton, FL, USA, 2006.

[17] For reviews, see: a) M. C. Pinto, J. A. García-Barrado, P. Macías, Recent Res. Devel. Biochem. 2004, 5, 281-290; b) B. Zhou, Z.-L. Liu, Pure Appl. Chem. 2005, 77, 1887-1903.

[18] For a review, see: G. L. Russo, Biochem. Pharmacol. 2007, 74, 533-544.

[19] For a review, see: A. Minerva, Cosmetic News 2006, 29, 398404.

[20] For a review, see: W.-X. Tian, Curr. Med. Chem. 2006, 13, 967977.

[21] For a review, see: H. I. Rocha-González, M. Ambriz-Tututi, V. Granados-Soto, CNS Neurosci. Ther. 2008, 14, 234-247.

[22] a) J. J. Heynekamp, W. M. Weber, L. A. Hunsaker, A. M. Gonzales, R. A. Orlando, L. M. Deck, D. L. Vander Jagt, J. Med. Chem. 2006, 49, 7182-7189; b) W. Zhang, M. L. Go, Eur. J. Med. Chem. 2007, 42, 841-850, and references cited therein; c) A. Gosslau, S. Pabbaraja, S. Knapp, K. Y. Chen, Eur. J. Pharmacol. 2008, 587, 25-34.

[23] a) S. Sale, R. D. Verschoyle, D. Boocock, D. J. L. Jones, N. Wilsher, K. C. Ruparelia, G. A. Potter, P. B. Farmer, W. P. Steward, A. J. Gescher, Br. J. Cancer 2004, 90, 736-744; b) S. Sale, R. G. Tunstall, K. C. Ruparelia, G. A. Potter, W. P. Steward, A. J. Gescher, Int. J. Cancer 2005, 115, 194-201; c) Z. Ma, O. Molavi, A. Haddadi, R. Lai, R. A. Gossage, Cancer Chemother. Pharmacol. 2008, 63, 27-35.
401 
[24] For reviews, see: a) F. Alonso, M. Yus, Chem. Soc. Rev. 2004, 33, 284-293; b) F. Alonso, M. Yus, Pure Appl. Chem. 2008, 80, $1005-1012$.

[25] a) F. Alonso, J. J. Calvino, I. Osante, M. Yus, Chem. Lett. 2005, 34, 1262-1263; b) F. Alonso, J. J. Calvino, I. Osante, M. Yus, J. Exp. Nanosci. 2006, 1, 419-433.

[26] a) F. Alonso, I. Osante, M. Yus, Adv. Synth. Catal. 2006, 348, 305-308; b) F. Alonso, I. Osante, M. Yus, Synlett 2006, $3017-$ 3020; c) F. Alonso, I. Osante, M. Yus, Tetrahedron 2007, 63, 93-102; d) F. Alonso, I. Osante, M. Yus, ARKIVOC 2008, 4, $8-15$.

[27] a) F. Alonso, P. Riente, M. Yus, Tetrahedron 2008, 64, 18471852; b) F. Alonso, P. Riente, M. Yus, Tetrahedron Lett. 2008, 49, 1939-1942.

[28] F. Alonso, P. Riente, M. Yus, Synlett 2008, 1289-1292.

[29] a) F. Alonso, P. Riente, M. Yus, Synlett 2007, 1877-1880; b) F. Alonso, P. Riente, M. Yus, Eur. J. Org. Chem. 2008, 4908-4914.

[30] a) F. Alonso, P. Riente, M. Yus, Synlett 2009, 1579-1582; b) F. Alonso, P. Riente, M. Yus, Tetrahedron Lett. 2009, 50, 30703073.

[31] This assertion is made on the basis that in every redox process a species is oxidised at the same time that the oxidant agent is reduced. In the present case, we assume that dehydrogenation of the alcohol occurs, leading to the intermediate aldehyde (the "oxidation" product). However, other species resulting from a reduction step are not detected.

[32] H. Yamataka, K. Nagareda, K. Ando, T. Hanafusa, J. Org. Chem. 1992, 57, 2865-2869.

[33] G. Belluci, C. Chiape, G. Lo Moro, Tetrahedron Lett. 1996, 37, 4225-4228.

[34] J. A. Widegren, R. G. Finke, J. Mol. Catal. A 2003, 198, 317341.
[35] M. A Alli, Y Tsuda, Chem Pharm. Bull 1992,

[36] M. B. Andrus, J. Liu, E. L. Meredith, E Nartey, Tetrahedron Lett. 2003, 44, 4819-4822.

[37] a) E. Bernard, P. Britz-Mc-Kibbin, N. Gernigon, J. Chem. Educ. 2007, 84, 1159-1161; b) V. Cardile, R. Chillemi, L. Lombardo, S. Sciuto, C. Spatafora, C. Tringali, Z. Naturforsch., Teil C 2007, 62, 189-195.

[38] Y. Asakawa, K. Tanikawa, T. Aratani, Phytochemistry 1976 $15,1057-1059$.

[39] M. Murias, N. Handler, T. Erker, K. Pleban, G. Ecker, P. Saiko, T. Szekeres, W. Jaeger, Bioorg. Med. Chem. 2004, 12, 55715578.

[40] a) M. Murias, W. Jaeger, N. Handler, T. Erker, Z. Horvath, T. Szekeres, H. Nohl, L. Gille, Biochem. Pharmacol. 2005, 69, 903-912; b) Z. Ovesna, K. Kozics, Y. Bader, P. Saiko, N. Handler, T. Erker, T. Szekeres, Oncol. Rep. 2006, 16, 617-624.

[41] a) P. Saiko, Z. Horvath, M. Murias, N. Handler, W. Jaeger, T. Erker, M. Fritzer-Szekeres, T. Szekeres, Nucleosides Nucleotides Nucleic Acids 2006, 25, 1013-1017; b) Z. Horvath, M. Murias, P. Saiko, T. Erker, N. Handler, S. Madlener, W. Jaeger, M. Grusch, M. Fritzer-Szekeres, G. Krupitza, T. Szekeres, Exp. Hematol. 2006, 34, 1377-1384.

[42] Z. Horvath, S. Marihart-Fazekas, P. Saiko, M. Grusch, M. Oezsuey, M. Harik, N. Handler, T. Erker, W. Jaeger, M. FritzerSzekeres, B. Djavan, T. Szekeres, Anticancer Res. 2007, 27, 3459-3464.

[43] P. Saiko, M. Pemberger, Z. Horvath, I. Savinc, M. Grusch, N. Handler, T. Erker, W. Jaeger, M. Fritzer-Szekeres, T. Szekeres, Oncol. Rep. 2008, 19, 1621-1626.

Received: August 21, 2009 
Nickel Nanoparticles

Nickel nanoparticles were found to activate primary alcohols, as phosphorus ylide partners, in a novel Wittig-type olefination reaction. A wide range of alkenes were prepared from both semi- and nonstabilised 536 ylides. The methodology was applied to the synthesis of a variety of polymethoxylated and polyhydroxylated stilbenes, such as

$$
\begin{gathered}
\mathrm{R}^{1}{ }_{\mathrm{OH}}+\mathrm{Ph}_{3} \mathrm{P}=\mathrm{R}^{2} \\
\mathrm{R}^{1}=\text { aryl, alkyl, } \mathrm{R}^{2}=\text { aryl } \\
\mathrm{R}^{1}=\text { aryl, } \mathrm{R}^{2}=\text { alkyl } \\
\qquad \begin{array}{c}
\text { NiNPs (1 equiv.) } \\
\mathrm{THF}, \text { reflux }
\end{array} \\
\mathrm{R}^{1} \mathrm{~N}_{\mathrm{r}} \mathrm{R}^{2} \\
30-99 \% \\
29 \text { examples }
\end{gathered}
$$

\section{F. Alonso, ${ }^{*}$ P. Riente, M. Yus* ….... 1-10}

Wittig-Type Olefination of Alcohols Promoted by Nickel Nanoparticles: Synthesis of Polymethoxylated and Polyhydroxylated Stilbenes

Keywords: Alcohols / Olefination / Nickel / Nanoparticles / Wittig reactions 